\title{
Theoretical Maximum Algal Oil Production
}

\author{
Kristina M. Weyer • Daniel R. Bush • Al Darzins • \\ Bryan D. Willson
}

Published online: 8 October 2009

(C) The Author(s) 2009. This article is published with open access at Springerlink.com

\begin{abstract}
Interest in algae as a feedstock for biofuel production has risen in recent years, due to projections that algae can produce lipids (oil) at a rate significantly higher than agriculture-based feedstocks. Current research and development of enclosed photobioreactors for commercialscale algal oil production is directed towards pushing the upper limit of productivity beyond that of open ponds. So far, most of this development is in a prototype stage, so working
\end{abstract}

Employees of the Alliance for Sustainable Energy, LLC, under Contract No. DE-AC36-08GO28308 with the U.S. Department of Energy have authored this work. The United States Government retains and the publisher, by accepting the article for publication, acknowledges that the United States Government retains a nonexclusive, paid-up, irrevocable, worldwide license to publish or reproduce the published form of this work, or allow others to do so, for United States Government purposes.

K. M. Weyer $(\bowtie)$

Solix Biofuels, Inc,

430B N. College Ave,

Fort Collins, CO 80524, USA

e-mail: kristina.weyer@solixbiofuels.com

D. R. Bush

Department of Biology, Colorado State University,

Fort Collins, CO 80523, USA

\section{A. Darzins}

National Bioenergy Center,

National Renewable Energy Laboratory,

1617 Cole Blvd,

Golden, CO 80401, USA

B. D. Willson

Department of Mechanical Engineering,

Engines and Energy Conversion Laboratory,

Colorado State University,

430 N. College Ave,

Fort Collins, CO 80524, USA production metrics for a commercial-scale algal biofuel system are still unknown, and projections are largely based on small-scale experimental data. Given this research climate, a methodical analysis of a maximum algal oil production rate from a theoretical perspective will be useful to the emerging industry for understanding the upper limits that will bound the production capabilities of new designs. This paper presents a theoretical approach to calculating an absolute upper limit to algal production based on physical laws and assumptions of perfect efficiencies. In addition, it presents a best case approach that represents an optimistic target for production based on realistic efficiencies and is calculated for six global sites. The theoretical maximum was found to be $354,000 \mathrm{~L} \cdot \mathrm{ha}^{-1} \cdot$ year $^{-1}\left(38,000 \mathrm{gal}^{-\mathrm{ac}^{-1}} \cdot \mathrm{year}^{-1}\right)$ of unrefined oil, while the best cases examined in this report range from 40,700-53,200 L $\cdot \mathrm{ha}^{-1} \cdot \mathrm{year}^{-1}\left(4,350-5,700 \mathrm{gal} \cdot \mathrm{ac}^{-1} \cdot \mathrm{year}^{-1}\right)$ of unrefined oil.

Keywords Algae - Biofuels · Theoretical yield . Oil production $\cdot$ Second-generation feedstock

$\begin{array}{ll}\text { Abbreviations } \\ \text { DCW } & \text { Dry cell weight } \\ \text { NREL } & \text { National Renewable Energy Laboratory } \\ \text { PAR } & \text { Photosynthetically active radiation } \\ \text { PCE } & \text { Photoconversion efficiency } \\ \text { PFD } & \text { Photon flux density }\end{array}$

\section{Introduction}

Algae as a feedstock is emerging at the forefront of biofuel research due to increasing awareness of global energy issues in conjunction with the production limitations of agriculturebased oilseed crops $[8,30]$. Many species of algae exhibit 
promise in this capacity because of their characteristics of high lipid content and rapid growth, which result in areal productivity significantly higher than oilseed crops. Additionally, because algae are grown in water rather than soil, algal production can be sited on land not suitable for agricultural use.

The potential of algae as a biofuels feedstock was investigated extensively by the Aquatic Species Program of the National Renewable Energy Laboratory (NREL), focusing specifically on open-pond production designs [31]. That program concluded that large-scale algal production could be an economically competitive source of renewable energy. Recent years have seen the emergence of new enclosed photobioreactor designs, which are expected to improve yields over the open-pond design by protecting productive strains from contamination and using higher surface-area-to-volume ratios to optimize light utilization. In light of the recent research, a calculation of the theoretical limits of algal production will provide a useful benchmark for understanding the yields that can be realistically expected from this new biofuel technology.

While numerous studies have addressed maximum theoretical efficiency of photosynthesis $[6,9,23,26]$, they have not been applied specifically to algal biofuel production or extrapolated to calculate maximum instantaneous efficiency and maximum annual production yield. Calculations by Raven [26] and Goldman [13] are the closest in methodology to this work, but they focus primarily on daily rather than annual yields and include assumptions of unknown efficiencies akin to the best-case approach in this work but do not address a purely theoretical case. Likewise, many projections have been made of expected production yields, but are frequently based on small-scale experiments or include estimations of future advances $[8,30,31]$.

The limits presented in this paper apply to any largescale algal production system that relies only on solar energy input to drive growth and oil production. Systems that use artificial lighting or other additional energy inputs, such as sugars for heterotrophic growth, are not considered. The calculation for theoretical maximum yield is based on physical laws, an established value for quantum yield, solar irradiance assuming perfectly clear weather and atmospheric conditions, and assumes $100 \%$ for unknown efficiencies. Thus, the theoretical maximum yield is a true upper limit: a value that cannot be surpassed without breaking fundamental physical laws. Due to the numerous assumptions of perfect efficiency employed in the theoretical calculation, it is an unattainable goal. A best case is also calculated, in order to provide designers with a realistic goal, which employs solar irradiance data for several sites and reasonable but optimistically high values for some efficiencies that were assumed to be $100 \%$ in the theoretical case. The best case therefore represents what may be possible with optimization of both biological and production systems. Uncertainties in several terms were used to provide error bars on both yield results. These values provide a benchmark against which to gauge predicted and achieved yields both to the designers of algae production systems and those seeking to implement the technology.

\section{Methods}

The primary physical law that limits the production capabilities of algae is the first law of thermodynamics, which states conservation of energy for any system: $\dot{E}_{\text {in }} \geq \dot{E}_{\text {stored }}$. For a system of photosynthesizing algae, $\dot{E}_{\text {in }}$ is the rate of incident solar irradiance on the production area, and $\dot{E}_{\text {stored }}$ is the rate of chemical energy storage by the algae as oil and other biomass. Thus, the amount of stored chemical energy is directly limited by the amount of solar irradiance available.

The intention of the theoretical maximum yield calculation is to provide a value that relies only on physical laws and well-known values so that it cannot be disputed as the upper limit to production. For this reason, several efficiencies that reasonably cannot be $100 \%$ have been conservatively included in the calculation as $100 \%$ because a value has not yet been well established. Thus, the calculated theoretical maximum yield is not dependent on estimates that could easily change depending on new experimental results or species. In contrast, optimistic estimates of known phenomena are included in the best case because the intention is to provide an optimistic production goal.

The equation to calculate total yield for both the theoretical and best cases is identical. The calculations differ only due to different values used for the two cases. The equation includes 11 terms and gives annual production yield, in volume area $^{-1} \cdot$ year $^{-1}$ of unrefined oil. Several subsets of the terms produce other metrics of note. The first three terms combined result in total photons of average energy in the photosynthetically active portion of the spectrum. Terms 3, 6, and 7 combined result in maximum photosynthetic efficiency, which is a measure of energy stored as biomass per incident solar energy. The first nine terms combined result in growth rate, given as mass area $^{-1}$. day $^{-1}$ of biomass.

\section{Term 1: Full-spectrum Solar Energy}

The term full-spectrum solar energy $\left(E_{\text {full-spectrum }}\right)$ represents the total solar irradiance incident on the algal production system. The solar spectrum is a function of atmospheric conditions (including clouds, aerosols, ozone, and other gases), which affect both the magnitude and 


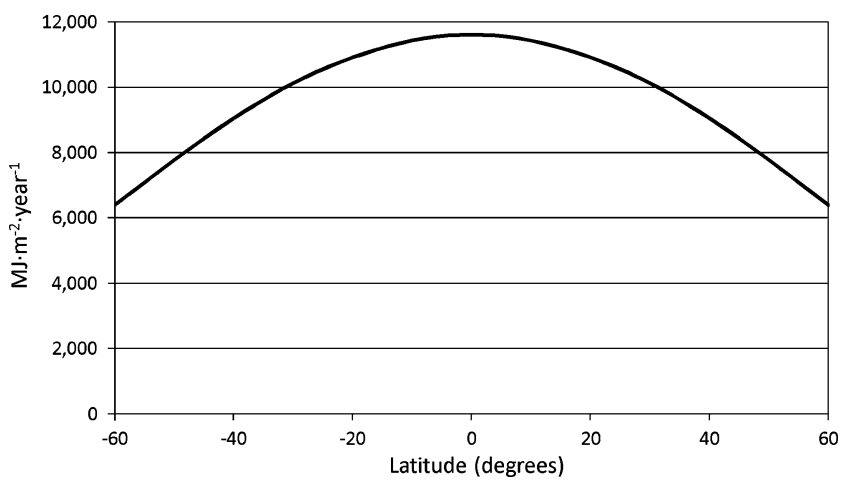

Fig. 1 Theoretical maximum annual solar irradiance as a function of latitude $\left(E_{\text {full-spectrum }}\right)$

spectral distribution of solar irradiance that reaches the earth's surface.

For the theoretical case, total solar irradiance was calculated assuming year-round clear skies and minimal atmospheric absorption. With these assumptions, theoretically maximum total solar irradiance is a function of latitude alone, shown in Fig. 1 for sea level. Calculations for this graph used the Bird Clear Sky Model [4], with the following inputs for minimal atmospheric absorption: $0.05 \mathrm{~cm}$ total column ozone thickness, $0.01 \mathrm{~cm}$ total column water vapor thickness, 0.02 aerosol optical depth at $500 \mathrm{~nm}$, and 0.1 aerosol optical depth at $380 \mathrm{~nm}$.

For the best case, total solar irradiance was calculated using weather data for six global climates, because the actual amount of irradiance is greatly reduced from the theoretical by clouds and other absorptive atmospheric conditions. Weather data that represents typical conditions were used from the Department of Energy's EnergyPlus weather data set [33]. The six sites and their latitudes are Denver, Colorado $\left(40^{\circ} \mathrm{N}\right)$; Phoenix, Arizona $\left(33^{\circ} \mathrm{N}\right)$; Honolulu, Hawaii $\left(21^{\circ} \mathrm{N}\right)$; Kuala Lumpur, Malaysia $\left(3^{\circ} \mathrm{N}\right)$; Tel Aviv, Israel $\left(32^{\circ} \mathrm{N}\right)$; and Màlaga, Spain $\left(37^{\circ} \mathrm{N}\right)$. Figure 2 shows a comparison of theoretical and actual values on an annual basis. As this figure shows, solar irradiance is strongly dependent on the climate, not only latitude. For example, Phoenix has the highest total annual solar irradiance despite its relatively high latitude. Kuala Lumpur, close to the equator and with the highest theoretical solar irradiance, has the lowest actual solar irradiance.

Term 2: Photosynthetic Portion of Spectrum

The term photosynthetic portion of spectrum (percent photosynthetically active radiation (PAR)) accounts for the fact that only a portion of the solar spectrum is utilizable for photosynthesis. That portion is known as PAR and is commonly defined as $400-700 \mathrm{~nm}$. The curve of intensity as a function of wavelength $\left(E_{\text {solar }}(\lambda)\right)$ was calculated with clear-sky assumptions using the SMARTS model $[16,17]$ (Fig. 3).

$E_{\text {solar }}(\lambda)$ was used to calculate term $2, \% \mathrm{PAR}$, the ratio of PAR to full-spectrum solar energy by Eq. 1, where $99 \%$ of the solar spectrum falls in $\lambda \leq 4000 \mathrm{~nm}$ :

$$
\begin{aligned}
\% \mathrm{PAR} & =\frac{\text { PAR energy }}{\text { Full- spectrum energy }} \times 100 \\
& =\frac{\int_{\lambda=400 \mathrm{~nm}}^{700 \mathrm{~nm}} E_{\text {solar }}(\lambda) d \lambda}{\int_{\lambda=0 \mathrm{~nm}}^{4000} E_{\text {solar }}(\lambda) d \lambda} \times 100
\end{aligned}
$$

\%PAR was calculated to be $45.8 \%$, which is in agreement with published literature [13, 14, 21]. \%PAR was assumed to be constant, though it does vary a small amount depending on the ratio of direct to diffusion solar irradiance.

It should be noted that although the entire 400-700 nm portion of the spectrum is considered to be "photosynthetically active", the absorption spectrum of chlorophyll for any oxygenic photosynthesizing organism absorbs best at the edges of this range (blue and red light), and not as well in the middle (green). Therefore, \%PAR may conservatively overestimate the actual solar energy available for photosynthesis.

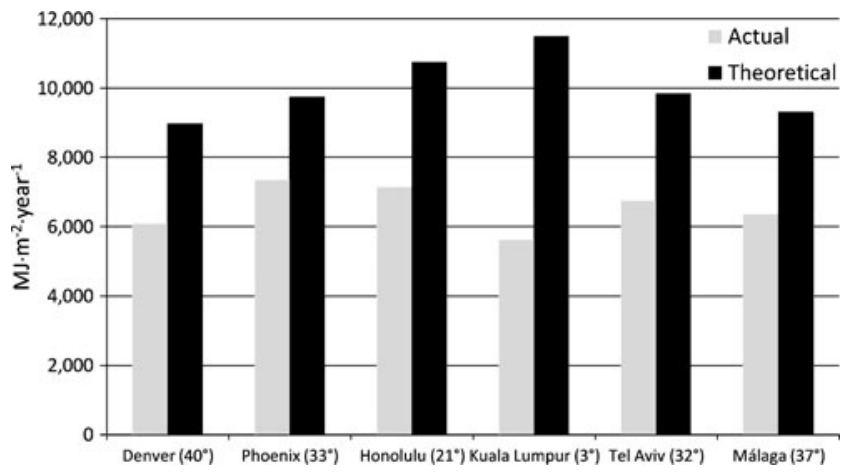

Fig. 2 Annual theoretical and actual solar irradiance by site

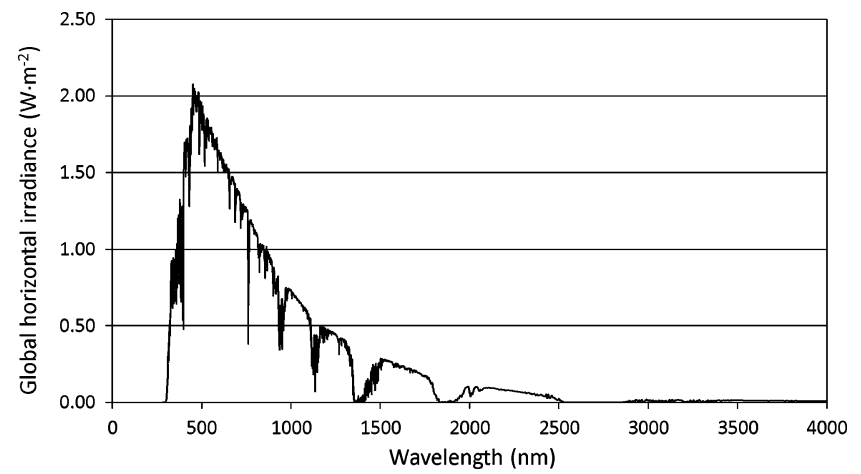

Fig. 3 Spectral distribution of solar irradiance $\left(E_{\text {solar }}(\lambda)\right)$ 


\section{Term 3: Photon Energy}

The term photon energy, $\left(\overline{E_{\text {photon }}}\right)$, converts PAR as energy to number of photons. $E_{\text {solar }}(\lambda)$, calculated in term 2, was used to calculate term 3 , the wavelength-weighted average photon energy, $\overline{E_{\text {photon }}}$. Within the PAR range, photon energy ranges from most energetic $\left(299 \mathrm{~kJ} \cdot \mathrm{mol}^{-1}\right)$ at $400 \mathrm{~nm}$ (blue) to least energetic $\left(171 \mathrm{~kJ} \cdot \mathrm{mol}^{-1}\right)$ at $700 \mathrm{~nm}$ (red). These are calculated using Planck's law ( $E_{\text {photon }}=h \cdot c / \lambda$, where $h$ is Planck's constant $(6.63 \mathrm{E}-34 \mathrm{~J} \cdot \mathrm{s}), c$ is the speed of light (2.998E $8 \mathrm{~m} \cdot \mathrm{s}^{-1}$ ), and $\lambda$ is wavelength). $\overline{E_{\text {photon }}}$ was calculated to be $225.3 \mathrm{~kJ} \cdot \mathrm{mol}^{-1}$, or $0.2253 \mathrm{MJ} \cdot \mathrm{mol}^{-1}$, also in good agreement with published values $[14,21]$. This corresponds to a wavelength of $531 \mathrm{~nm}$ (green).

Total photon flux density (PFD) over a year can be calculated from a combination of terms 1, 2, and 3 by Eq. 2 .

$\operatorname{PFD}\left(\frac{\text { mol }}{\mathrm{m}^{2} \cdot \text { year }}\right)=\frac{E_{\text {full }- \text { spectrum }}\left(\frac{\mathrm{MJ}}{\mathrm{m}^{2} \cdot \text { year }}\right) \times \frac{\% \mathrm{PAR}}{100}}{\bar{E}_{\text {photon }}\left(\frac{\mathrm{MJ}}{\mathrm{mol}}\right)}$

Term 4: Photon Transmission Efficiency

The term photon transmission efficiency accounts for losses in incident solar energy due to the construction or geometry of the growth system, either an open-pond or enclosed photobioreactor. Light reflection or absorption by surfaces and materials will be minimized in an optimized design, but any design will have some reduction in the number of incident photons that reach the cells. For the theoretical case, the growing system was assumed to preserve total PFD, i.e., no reduction to $100 \%$ photon transmission efficiency. For the best case, the reduction in PFD due to the growth system was estimated for an open-pond scenario, where incident solar energy is lost due to reflection off the open water surface. Solar geometry equations [10] were used to calculate two parameters: reflectance off the surface based on angle of incidence and the predicted magnitude of solar radiation (assuming no cloud cover) for any given latitude, day of year,

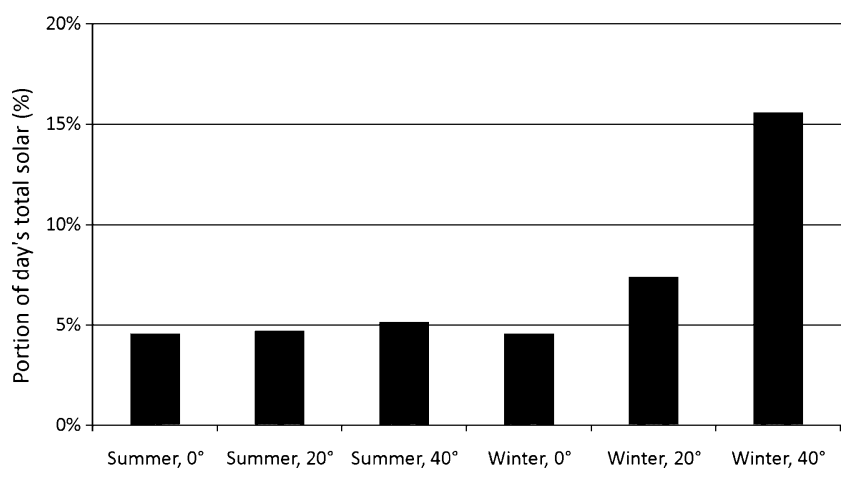

Fig. 4 Reflected incident solar for open water surface, by latitude and solstice and time of day. Larger angles of incidence, and thus more reflection, occur during the early and late hours of the day when the sun is lower in the sky, but the incident solar energy during these hours is also lower at these times. The two parameters were multiplied and summed over a day period to find an estimate of the total portion of a day's solar energy lost due to reflection. Results for the summer and winter solstices for latitudes $0^{\circ}, 20^{\circ}$, and $40^{\circ}$ are shown in Fig. 4 .

Based on the results of this analysis, for the best case, the reduction in PFD due to growth system geometry was assumed to be $5 \%$, resulting in a photon transmission efficiency of $95 \%$.

\section{Term 5: Photon Utilization Efficiency}

The term photon utilization efficiency accounts for reductions in perfect photon absorption due to suboptimal conditions of the algal culture. A cell under optimal conditions will absorb and use nearly all incident photons. However, under suboptimal conditions such as high-light levels or non-optimal temperatures under which photoinhibition occurs, some absorbed photons will be re-emitted as heat or cause damage to the cells. For the theoretical case, the culture was assumed to be maintained under perfectly optimal conditions such that all incident photons would be absorbed and used, i.e., there would be no reduction in the $100 \%$ photon utilization efficiency. For the best case, reduction in photon utilization due to high-light levels can be significant for outdoor production, and the magnitude of this effect varies with species, light, and other ambient conditions such as temperature. Light utilization efficiency could range from $50-90 \%$ under low-light conditions to $10-30 \%$ under high-light conditions [13]. Therefore, for the best case, a median value of $50 \%$ was chosen, which may be conservatively high, given that high-light conditions are likely to be found in outdoor growth systems.

Terms 6 and 7: Quantum Requirement and Carbohydrate Energy Content

The terms quantum requirement and carbohydrate energy content together represent the conversion of light energy to chemical energy via photosynthesis. The basic equation for photosynthesis is commonly expressed by Eq. 3:

$\mathrm{CO}_{2}+\mathrm{H}_{2} \mathrm{O}+8$ photons $\rightarrow \mathrm{CH}_{2} \mathrm{O}+\mathrm{O}_{2}$

This equation represents a combination of two reactions: (1) energy transduction in the two photosystems, which produces adenosine triphosphate (ATP) and nicotinamide adenine dinucleotide phosphate (NADPH) via electron transfer stimulated by photon absorption, and (2) carbon assimilation in the Calvin cycle, which uses the energy of 
the ATP and NADPH produced in the photosystems to fix $\mathrm{CO}_{2}$ and produce chemical energy.

Term 6, quantum requirement, represents the energy input on the left side of Eq. 3 of $8 \mathrm{~mol}$ photons per mol of $\mathrm{CO}_{2}$ reduced to $\mathrm{CH}_{2} \mathrm{O}$. At perfect efficiency, the quantum requirement would be 3 , because 3 of the least energetic photons (at $700 \mathrm{~nm}$ ) have an energy of $3 \times 170.9 \mathrm{~kJ} \cdot \mathrm{mol}^{-1}=$ $512.7 \mathrm{~kJ} \cdot \mathrm{mol}^{-1}$. This is slightly higher than the required energy of $482.5 \mathrm{~kJ} \cdot \mathrm{mol}^{-1}$. However, extensive debates on this topic since the middle of the last century have resulted in a common agreement that the value of $8 \mathrm{~mol}$ photons per mol $\mathrm{CO}_{2}$ reduced to $\mathrm{CH}_{2} \mathrm{O}$ corresponds to maximally efficient photosynthesis based on the Z-scheme $[6,11,15,23,25$, 34]. While some researches might argue that higher values may be more realistic, because of our methodology of conservatism to produce an absolute maximum, 8 was used because there is not yet consensus on a higher (and thus less efficient) theoretical quantum requirement.

In Eq. 3, $\mathrm{CH}_{2} \mathrm{O}$ represents the basic form of chemical energy captured by photosynthesis. Its actual form is triosephosphate $\left(\mathrm{C}_{3} \mathrm{H}_{5} \mathrm{O}_{3} \mathrm{P}\right)$, but the energy content is often calculated from glucose $\left(\mathrm{C}_{6} \mathrm{H}_{12} \mathrm{O}_{6}\right)$. Several reported values for $\mathrm{CH}_{2} \mathrm{O}$ include 496, 494, 468.9, and $470 \mathrm{~kJ} \cdot \mathrm{mol}^{-1}[6,13$, $29,34]$. The median of the range of cited values, $482.5 \mathrm{~kJ} \cdot \mathrm{mol}^{-1}$, was used for term 7, carbohydrate energy content.

\section{Term 8: Biomass Accumulation Efficiency}

The term biomass accumulation efficiency accounts for energy that is used for cellular functions rather than stored directly as biomass. Thus, it is the ratio of the chemical energy stored in the cell as biomass to the total energy captured. During normal growth, energy required by the cell may be retrieved by consuming carbohydrates already stored, or by using ATP directly. All cell functions that require energy are included in this term, such as maintenance, repair, and synthesis of complex molecules (including oils). The complexities of energy use considered by biomass accumulation efficiency are not well understood and are highly dependent on factors such as species, temperature, and nitrogen source. Therefore, because the methodology of the theoretical case seeks to avoid disputable assumptions, term 8 was considered to be $100 \%$, perfect efficiency of biomass accumulation, implying that the cell does not require any of its captured energy to maintain itself or synthesize complex molecules.

For the best case, the "cost of living" accounted for by this term was estimated from a survey of a variety of sources, some of which consider only respiration, and others which consider cell energy use comprehensively. Sukenik et al. [32] estimated that the costs of living consume $35 \%$ of the total energy captured by photosynthesis, meaning a biomass accumulation efficiency of $65 \%$. Falkowski et al. [12] cited values of
$47-86 \%$ for what the authors call "net growth efficiency" for various species and irradiances. Langdon [22] reported values for a respiration to gross production ratio of $21-89 \%$ for various species, which translates to $11-79 \%$ for this efficiency term. Goldman [13] used an estimate of $87.5 \%$. In contrast, Zhu et al. estimated a $66 \%$ percent loss of energy in carbohydrate synthesis in higher plants, which translates to $34 \%$ for this term [35]. Given this wide range of estimated values, for the best case, a value of $50 \%$ was chosen for biomass accumulation efficiency.

\section{Term 9: Biomass Energy Content}

The term biomass energy content describes how much biomass will be produced for the amount of captured energy, also called heat of combustion. Values cited in other literature range from 20 to $23.75 \mathrm{~kJ} \cdot \mathrm{g}^{-1}[1,3,13,20,31]$. Energy content can also be calculated via weighted average of proteins, carbohydrates, and oil, with energy contents 16.7,

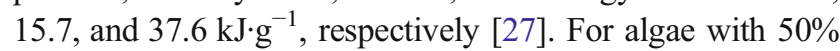
oil content (assumed in term 10, below), energy content by this method is $26.9 \mathrm{~kJ} \cdot \mathrm{g}^{-1}$. However, a value of $21.9 \mathrm{~kJ} \cdot \mathrm{g}^{-1}$, the median of the range from the literature, was chosen because it represents the energy content during the growth of the culture rather than the oil-laden state just before harvest.

Terms 1 through 9 combined result in total biomass growth rate, usually expressed as $\mathrm{g} \cdot \mathrm{m}^{-2} \cdot \mathrm{day}^{-1}$.

\section{Term 10: Cell Oil Content}

The term cell oil content is the portion of the cell that can be refined into a usable biofuel. A theoretical maximum value is not yet known for a cell's oil content, and oil content is highly specific to species and growth conditions. Most values reported in the literature are total lipid content of dry cell weight (DCW). Chisti [8] presented a summary of algal lipid contents ranging from $15 \%$ to $77 \%$ DCW. Rodolfi et al. [28] presented cited values as high as $70 \%$ and $85 \%$ DCW, but also note that lipid accumulation often corresponds with reduced biomass productivity, so the high-growth requirement of production systems may necessitate species with lower lipid content and higher growth rates. A recent comprehensive survey by $\mathrm{Hu}$ et al. [19] showed an average total lipid content for oleaginous green algae of $45.7 \%$ DCW under stress conditions. However, while the oil extracted from algal biomass can readily be converted into a usable biofuel, it is not yet clear how much of the remaining cellular lipids can also be converted. An additional overestimation may be introduced because most of the values reported in the literature are based on gravimetric analysis, which may overestimate total lipid content by co-extracting some non-lipid components such as proteins, carbohydrates, and pigments. For 
this work, $50 \%$ oil content was chosen for both the theoretical and best cases, though it is acknowledged this may be an overestimate of what will be achievable for production systems for the reasons stated above.

\section{Term 11: Oil Density}

The term oil density is the volumetric density of the unrefined oil. This term converts the mass of oil produced to a volume measurement. Because algal oil is a relatively new commodity, not much data exist for its physical properties. Therefore, the density of soybean oil, which is similar to algal oil, was used. The density of soybean oil was taken to be $918 \mathrm{Kg} \cdot \mathrm{m}^{-3}$, with a range of 910 $925 \mathrm{Kg} \cdot \mathrm{m}^{-3}$ [5] for both the theoretical and best cases.

\section{Results}

The values used in the calculations and the resulting outputs for the theoretical and best cases are summarized in Table 1. The daily maximum growth for the theoretical case used the daily average, assuming sustained year-round production, because the theoretical case assumed a site on the equator, which has relatively constant solar irradiance. The daily maximum growth for the best case used the day with peak solar energy, and thus represents a rate that could be achieved over short periods, but not sustained, unless the site sustained a high rate of solar energy, such as those close to the equator.
The uncertainties in terms $1,7,9$, and 11 should be taken into account, and these were used to add error bars to the results. These are the only terms included because the others are assumptions appropriate to the methodology (terms 4, 5, 8, and 10) or are well-established values (term 6). Any uncertainty in terms 2 and 3 is assumed to be captured in the uncertainty in term 1. The effect of the collective uncertainty in terms $1,7,9$, and 11 on the final result was calculated by using the sets of values that maximally increase or decrease the final result. For example, if the result were calculated from $C=A / B$, then the highest possible result due to the uncertainties would be calculated from $C_{\text {high }}=(A+\Delta A) /(B-\Delta B)$, and the lowest possible result would be calculated from $C_{\text {low }}=(A-\Delta A) /(B+\Delta B)$, where $\Delta A$ and $\Delta B$ are the errors associated with terms $\mathrm{A}$ and $\mathrm{B}$.

The uncertainties in terms 1, 7, 9, and 11 are illustrated by the error bars in Figs. 5 and 6. For term 1, full-spectrum solar energy, an uncertainty of $\pm 10 \%$ was used for the theoretical calculation of total solar based on the two radiation models employed. Term 1 for the best case has no uncertainty because the dataset is derived from several decades of data and represents typical weather conditions. For terms 7,9 , and 11 , uncertainties of $2.2 \%, 8.4 \%$, and $1 \%$, respectively, were taken from the ranges of cited values found in the literature. Error bars in Fig. 5 increase with latitude because they are calculated as a percent of term 1 , the total solar energy for a particular latitude.

Because the theoretical case uses the assumption of an equatorial site with perfectly clear skies, it represents an

Table 1 Results for theoretical and best cases

\begin{tabular}{llll}
\hline Term & Theoretical case & Best case & Units \\
\hline (1) Full-spectrum solar energy & 11,616 & $5,623-7,349$ & ${\mathrm{MJ} \cdot \mathrm{m}^{-2} \cdot \mathrm{year}^{-1}}$ \\
(2) Photosynthetic portion of spectrum & $45.8 \%$ & $45.8 \%$ & - \\
(3) Photon energy & $225.3 \mathrm{E}-3$ & $225.3 \mathrm{E}-3$ & $\mathrm{MJ}^{-3} \mathrm{~mol}^{-1}$ \\
(4) Photon transmission efficiency & $100 \%$ & $95 \%$ & - \\
(5) Photon utilization efficiency & $100 \%$ & $50 \%$ & - \\
(6) Quantum requirement & 8 & 8 & $\mathrm{~kJ} \cdot \mathrm{mol}^{-1}$ \\
(7) Carbohydrate energy content & 482.5 & 482.5 & - \\
(8) Biomass accumulation efficiency & $100 \%$ & $50 \%$ & $\mathrm{~kJ} \cdot \mathrm{kg}^{-1}$ \\
(9) Biomass energy content & $21.9 \mathrm{E} 3$ & $21.9 \mathrm{E} 3$ & - \\
(10) Cell oil content & $50 \%$ & $50 \%$ & $\mathrm{~kg} \cdot \mathrm{m}^{-3}$ \\
(11) Oil density & 918 & 918 & $\mathrm{~g} \cdot \mathrm{m}^{-2} \cdot \mathrm{day}^{-1}$ \\
Maximum daily growth & 196 & $33-42$ & $\mathrm{~L}^{-1} \mathrm{ha}^{-1} \cdot \mathrm{year}^{-1}\left(\mathrm{gal}^{-1} \cdot \mathrm{ac}^{-1} \cdot \mathrm{year}{ }^{-1}\right)$ \\
Annual oil production & $354,000(38,000)$ & $40,700(4,350)$ Kuala Lumpur &
\end{tabular}


Fig. 5 Theoretical case yield as a function of latitude

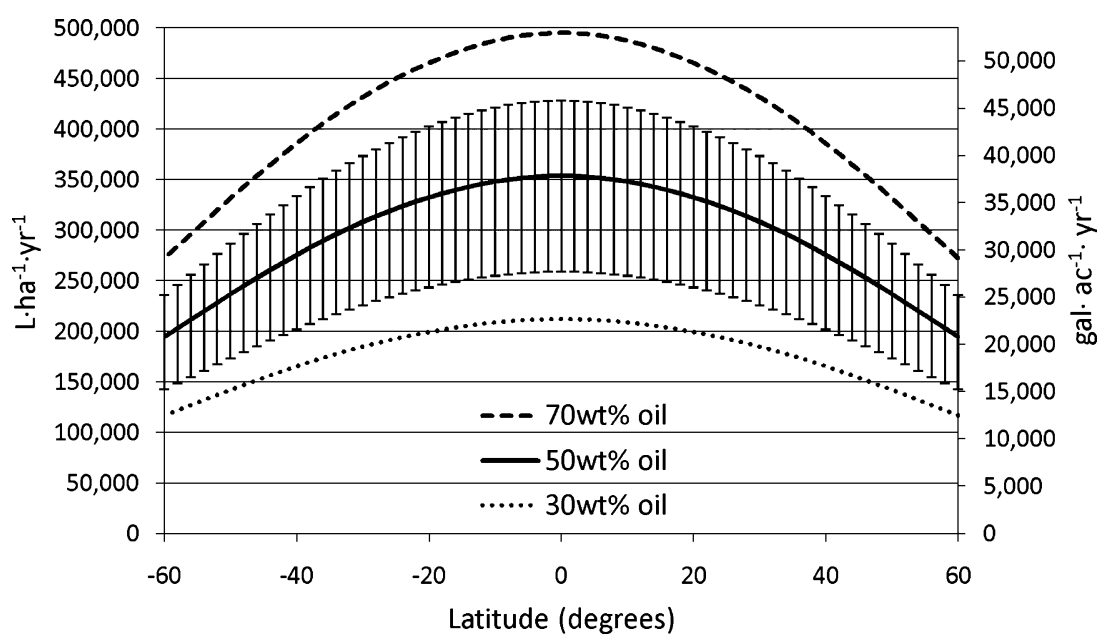

unattainable maximum for any location, and it is also much higher than the theoretical limit for any particular site off the equator with realistically cloudy weather. Because the amount of solar energy available is fixed and known from weather data, an additional case can be calculated: a theoretical case using actual solar data for specific sites. This modification only changes term 1 (fullspectrum solar energy) in the theoretical case. The theoretical maximum yields for the six sites chosen in the paper range from 171,000 to $224,000 \mathrm{~L} \cdot \mathrm{ha}^{-1} \cdot \mathrm{year}^{-1}(18,300$ to $24,000 \mathrm{gal}^{\mathrm{ac}} \mathrm{ac}^{-1} \cdot \mathrm{year}^{-1}$ ), for Kuala Lumpur and Phoenix, respectively. This case compared to the best case for the six sites is shown in Fig. 7.

\section{Discussion}

The best case agrees well with other projections and reported experimental results, where results were obtained from a system that uses only solar energy input to drive growth. The Aquatic Species Program report by NREL included projections based on experiments ranging from 50 to $300 \mathrm{mt} \cdot \mathrm{ha}^{-1} \cdot$ year $^{-1}$, which is equivalent to $2,913-$ $17,478 \mathrm{gal}^{\mathrm{ac}} \mathrm{ac}^{-1} \cdot \mathrm{year}^{-1}$ [31]. Chisti [8] predicted yields of 6,276-14,637 gal $\mathrm{ac}^{-1}$.year ${ }^{-1}$ for 30-70 wt.\% oil, respectively, which are somewhat more optimistic than the best case of this paper, but the climate was unspecified. Other reported projects were often expressed as daily biomass yield, rather than annual oil yield. Daily biomass yields rates reported in the published literature ranged from 10 to $37 \mathrm{~g} \cdot \mathrm{m}^{-2} \cdot \mathrm{day}^{-1}$, average for the production length in a variety of sites; peak rates ranged from 24 to $65 \mathrm{~g} \cdot \mathrm{m}^{-2}$. day ${ }^{-1}$ [2]. The recent work by Rodolfi et al. [28] predicted yields of 3,490 gal $\cdot \mathrm{ac}^{-1} \cdot \mathrm{year}^{-1}$ for tropical climates, which falls at the lower end of the best-case range.

The results cited above also agree well with other reported calculations of theoretical maximum production. Raven [26] calculated a range of theoretical maximum yields for various quantum requirement assumptions; for a quantum requirement of 8 , Raven calculated $173 \mathrm{~g} \cdot \mathrm{m}^{-2} \cdot \mathrm{day}^{-1}$. The assumed solar energy in that paper $\left(42.5 \mathrm{MJ} \cdot \mathrm{m}^{-2} \cdot \mathrm{day}^{-1}\right)$ is higher than the assumed solar energy in this paper but is based on an

Fig. 6 Best case yield by site

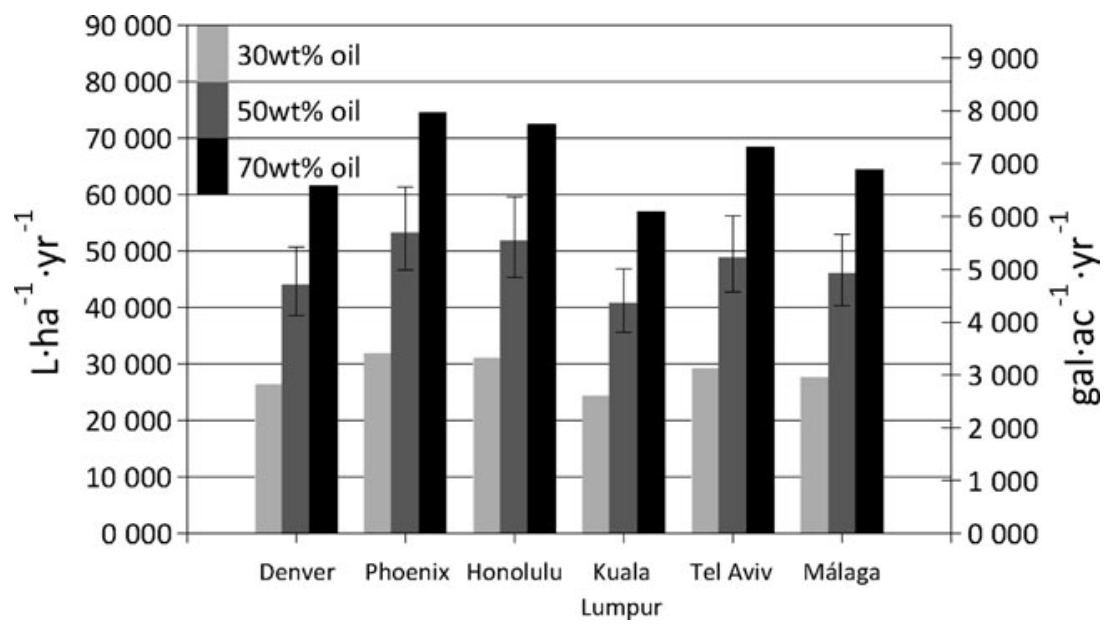


Fig. 7 Theoretical and best case, using actual solar data for both

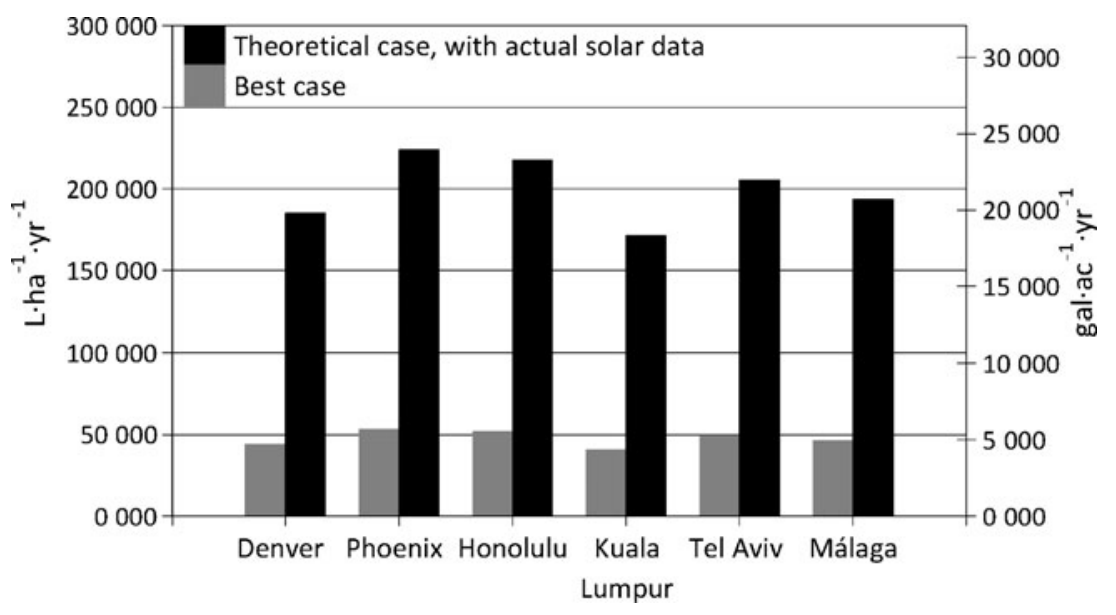

assumption of noontime equator sunlight for a 12-h day. Goldman's [13] calculation of a production maximum of $58 \mathrm{~g} \cdot \mathrm{m}^{-2} \cdot \mathrm{day}^{-1}$, from a solar input of $33.5 \mathrm{MJ} \cdot \mathrm{m}^{-2} \cdot \mathrm{day}^{-1}$, closely matched the best case of this paper.

The main differences among approaches to calculating a theoretical maximum involve the assumed solar irradiance, which is the main driving force for photosynthesis, and the quantum requirement. This paper addresses these differences by conservatively choosing values that will maximize the theoretical limit, thus presenting it as a true maximum that cannot be attained in any location.

A calculation of photoconversion efficiency (PCE) for algae can be made for the theoretical and best-case approaches for comparison to what is observed in terrestrial plants. This maximum theoretical PCE applies to any photosynthesizing organism and is given by Eq. 4 (based on PAR rather than full-spectrum solar irradiance):

$$
\begin{aligned}
\mathrm{PCE}_{\mathrm{PAR}} & =\frac{482.5\left(\frac{\mathrm{kJ}}{\mathrm{mol} \mathrm{CH}_{2} \mathrm{O}}\right)}{8\left(\frac{\mathrm{mol} \mathrm{photons}}{\mathrm{mol} \mathrm{CH}_{2} \mathrm{O}}\right) \times 225.3\left(\frac{\mathrm{kJ}}{\text { mol photons }}\right)} \\
& =26.7 \%
\end{aligned}
$$

This would be the PCE value for the theoretical case of perfectly efficient algae. For the best case, the reductions in perfect efficiency from terms 4,5 , and 8 of $95 \%, 50 \%$, and $50 \%$, respectively, result in a PCE of $6.3 \%$. In outdoor cultures of Chlorella in full sunlight, Burlew [7] achieved 2.6-2.7\% PCE based on PAR; for reduced sunlight (reduced to 22\%), he achieved 6.3\%. Most terrestrial plants are usually assumed to convert approximately $0.1 \%$ of solar energy into biomass. Zhu et al. [35] reported that the highest efficiencies achieved are $2.4 \%$ and $3.7 \%$ for $\mathrm{C} 3$ and $\mathrm{C} 4$ crops, respectively. Even crops considered to be highproductivity, such as the perennial grass Miscanthus, achieve only up to $1-2 \%$ PCE, based on PAR [18].
The calculation methodology of this paper makes evident the areas of focus for maximizing oil production. Just four of the 11 terms used in this calculation reduce the best case from the theoretical full-spectrum solar energy (term 1), which accounts for the total solar energy available; photon transmission efficiency (term 4), which accounts for losses through the growth system geometry; photon utilization efficiency (term 5), which accounts for losses due to photoinhibitive and other growth inhibiting effects; and biomass accumulation efficiency (term 8), which accounts for cellular energy requirements. The first is influenced only by site selection and can be easily calculated from weather data. Of the latter three, photon transmission efficiency may be increased through careful design of growth system geometry. Photon utilization efficiency may be maximized by distributing incident light broadly over a wide surface area or strain improvements that improve a species' tolerance to high-light levels. The costs associated with the last, biomass accumulation efficiency, are unavoidable because all cells require some of their captured energy for maintenance and growth, but species selection and other factors such as temperature will influence the magnitude. The success of algal production systems will largely be a function of how well the system is optimized to improve these efficiencies by providing optimal conditions for growth and lipid storage.

While the best case includes the estimates for efficiencies that may be improved with optimization of the growth system and algal strain, the theoretical case includes no estimates and thus continues to represent an unattainable limit despite system optimization and even genetic improvements to algal strains. Any possible strain improvements would be aimed at improvements in the efficiencies included in the best case (terms 4,5 , or 8 ). These might include decreasing photoreceptor antennae to reduce photoinhibitive effects, increasing temperature tolerance, or improving resistance to predatory species [24, 31]. These 
effects are already assumed to be nonexistent in the theoretical case.

Despite any discrepancies among approaches, all estimates affirm the productive potential of algae as a biofuel feedstock. The lowest projection in this paper, 40,700 L·ha ${ }^{-1}$ year ${ }^{-1}$

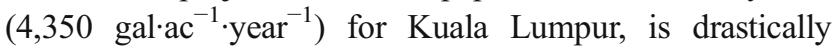
higher than reported yields for corn, canola, or even oil palm $\left(172,1190\right.$, and $5,950 \mathrm{~L} \cdot \mathrm{ha}^{-1} \cdot$ year $^{-1} ; 18,127$, and $637 \mathrm{gal} \cdot \mathrm{ac}^{-1} \cdot$ year $^{-1}$, respectively) [8]. Thus, the bounds on algal production presented in this paper should not be viewed as unpleasant news about physical realities but as a realistic check that confirms its potential and will serve the industry in its pursuit of maximum algal biofuel production.

\section{Conclusion}

A process of employing basic physical laws, known values, and conservative assumptions has resulted in a robust calculation of theoretical maximum and best case algal oil yields. For the theoretical case on the equator with $50 \%$ cell oil content, the theoretical maximum annual oil production from algae was calculated to be $354,000 \mathrm{~L} \cdot \mathrm{ha}^{-1} \cdot \mathrm{year}^{-1}$ $\left(38,000 \mathrm{gal}^{\circ} \mathrm{ac}^{-1} \cdot \mathrm{year}^{-1}\right)$ with an uncertainty of roughly $10 \%$. The best case was calculated to range from $40,700-$

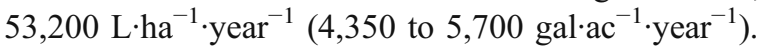

The equations, calculations, and discussion in this paper have shown that, because physical laws dictate the theoretical maximum, it represents a true upper limit to production that cannot be attained regardless of new technology advances. However, if algal biofuel production systems approach even a fraction of the calculated theoretical maximum, they will be extremely productive compared to current oil production capability of agriculture-based biofuels.

Acknowledgements The authors acknowledge the following individuals for their critical review of the manuscript: Michael Seibert, Eric Jarvis, Lieve Laurens (National Renewable Energy Laboratory), and Matthew Posewitz (Colorado School of Mines).

Open Access This article is distributed under the terms of the Creative Commons Attribution Noncommercial License which permits any noncommercial use, distribution, and reproduction in any medium, provided the original author(s) and source are credited.

\section{References}

1. Acièn Fernández F-G, Garcìa Camacho F, Sànchez Pérez J-A, Fernàndez Sevilla J-M, Molina Grima E (1998) Modeling of biomass productivity in tubular photobioreactors for microalgal cultures: effects of dilution rate, tube diameter, and solar irradiance. Biotechnol Bioeng 58(6):605-616
2. Becker E-W (1994) Microalgae: biotechnology and microbiology. Cambridge University Press, Cambridge

3. Ben-Amotz A (2007) Biofuel and CO2 capture by algae. Paper presented at the Algae Biomass Summit, San Francisco, 15 Nov 2007

4. Bird R-E, Hulstrom R-L (1981) Simplified clear sky model for direct and diffuse insolation on horizontal surfaces. Technical Report No. SERI/TR-642-761. Solar Energy Research Institute

5. Bockisch M (1998) Fats and oils handbook. AOCS Press, Champaign

6. Bolton J, Hall D (1991) The maximum efficiency of photosynthesis. Photochem Photobiol 53(4):545-548

7. Burlew J-S (1953) Algal culture: from laboratory to pilot plant. Carnegie Institution of Washington Publication, Washington DC

8. Chisti Y (2007) Biodiesel from microalgae. Biotechnol Adv 25:294-306

9. Cornet J-F, Dussap C-G, Gros J-B (1994) Conversion of radiant light energy in photobioreactors. AIChE J 40(6):1055-1066

10. Duffie J-A, Beckman W-A (2006) Solar engineering of thermal processes. Wiley, Hoboken

11. Falkowski P-G, Raven J-A (2007) Aquatic photosynthesis. Princeton University Press, Princeton

12. Falkowski P-G, Dubinsky Z, Wyman K (1985) Growthirradiance relationships in phytoplankton. Limnol Oceanogr 30(2):311-321

13. Goldman J (1979) Outdoor algal mass cultures - II. Photosynthetic yield limitations. Water Res 13:119-136

14. González J-A, Calbó J (2002) Modelled and measured ratio of PAR to global radiation under cloudless skies. Agric For Meteorol 110:319-325

15. Govindjee R, Rabinowitch E, Govindjee (1968) Maximum quantum yield and action spectrum of photosynthesis and fluorescence in Chlorella. Biochim Biophys Acta 162:539-544

16. Gueymard C (1995) SMARTS, a simple model of the atmospheric radiative transfer of sunshine: algorithms and performance assessment. Professional Paper FSEC-PF-270-95. Florida Solar Energy Center

17. Gueymard C (2001) Parameterized transmittance model for direct beam and circumsolar spectral irradiance. Sol Energy 71(5):325346

18. Heaton E-A, Dohleman F-G, Long S-P (2008) Meeting US biofuel goals with less land: the potential of Miscanthus. Glob Chang Biol 14:2000-2014

19. Hu Q, Sommerfield M, Jarvis E, Ghirardi M, Posewitz M, Seibert $M$ et al (2008) Microalgal triacylglycerols as feedstocks for biofuel production: perspectives and advances. Plant J 54:621639

20. Huntley M, Redalje D (2006) CO2 mitigation and renewable oil from photosynthetic microbes: a new appraisal. Mitig Adapt Strategies Glob Chang 12(4):573-608

21. Jacovides C-P, Timvios F-S, Papaioannou G, Asimakopoulos DN, Theofilou C-M (2004) Ratio of PAR to broadband solar radiation measured in Cyprus. Agric For Meteorol 121:135-140

22. Langdon C (1993) The significance of respiration in production measurements based on oxygen. ICES Mar Sci Symp 197:69-78

23. Lawlor D-W (1987) Photosynthesis: metabolism, control and physiology. Longman Scientific \& Technical, Essex

24. Melis A, Neidhardt J, Benemann J-R (1999) Dunaliella salina (Chlorophyta) with small chlorophyll antenna sizes exhibit higher photosynthetic productivities and photon use efficiencies than normally pigmented cells. J Appl Phycol 10:515-525

25. Raven J-A (1974) Photosynthetic electron flow and photophosphorylation. In: Stewart W-D-P (ed) Algal physiology and biochemistry. University of California Press, Berkeley 
26. Raven J-A (1988) Limits to growth. In: Borowitzka M, Borowitzka L (eds) Micro-algal biotechnology. Cambridge University Press, Cambridge

27. Rebolloso-Fuentes M-M, Navarro-Pèrez A, Garcìa-Camacho $F$, Ramos-Miras J-J, Guil-Guerrero J-L (2001) Biomass nutrient profiles of the microalga Nannochloropsis. J Agric Food Chem 49:2966-2972

28. Rodolfi L, Zittelli G-C, Bassi N, Padovani G, Biondi N, Bonini G et al (2008) Microalgae for oil: strain selection, induction of lipid synthesis and outdoor mass cultivation in a low-cost photobioreactor. Biotechnol Bioeng 102(1):100-112

29. Ryther J-H (1959) Potential productivity of the sea. Science 130:602-608

30. Schenk P, Thomas-Hall S, Stephens E, Marx U, Mussgnug J, Posten C et al (2008) Second generation biofuels: high-efficiency microalgae for biodiesel production. Bioenergy Res 1:20-43
31. Sheehan J, Dunahay T, Benemann J, Roessler P (1998) Look back at the U.S. Department of Energy's Aquatic Species Program: biodiesel from algae; Close-Out Report. NREL Report No. TP$580-24190$

32. Sukenik A, Levy R-S, Levy Y, Falkowski P-G, Dubinsky Z (1991) Optimizing algal biomass production in an outdoor pond: a simulation model. J Appl Phycol 3:191-201

33. U.S. Department of Energy (2009) EnergyPlus Weather Data. http://apps1.eere.energy.gov/buildings/energyplus/cfm/weather data.cfm. Cited 30 Jul 2009

34. Walker D (1992) Energy, plants and man. Packard Publishing Limited, East Sussex

35. Zhu X, Long S, Ort D (2008) What is the maximum efficiency with which photosynthesis can convert solar energy into biomass? Curr Opin Biotechnol 19:153-159 